\title{
Social capital and quality of life in adolescent apprentices in Brazil: An exploratory study
}

\author{
Ana Cristina Viana Campos ${ }^{1^{*}}$, Carolina Marques Borges ${ }^{2}$, Cláudio Rodrigues Leles $^{3}$, \\ Simone Dutra Lucas ${ }^{1}$, Efigênia F. Ferreira ${ }^{1}$ \\ ${ }^{1}$ Department of Social and Preventative Dentistry, School of Dentistry, Federal University of Minas Gerais, Belo Horizonte, Brazil; \\ *Corresponding Author: campos.acv@gmail.com \\ ${ }^{2}$ Department of Dentistry, Faculty of Management Studies of Minas Gerais, Belo Horizonte, Brazil \\ ${ }^{3}$ Department of Prevention and Oral Rehabilitation, School of Dentistry, Federal University of Goias, Goiania, Brazil
}

Received 16 March 2013; revised 16 April 2013; accepted 15 May 2013

Copyright (c) 2013 Ana Cristina Viana Campos et al. This is an open access article distributed under the Creative Commons Attribution License, which permits unrestricted use, distribution, and reproduction in any medium, provided the original work is properly cited.

\section{ABSTRACT}

Background: Adolescents who rely on social aid networks tend to be more socially competent and enjoy higher levels of quality of life than those who interact only with their own limited groups of family and friends. In this light, the present study aimed to measure social capital and analyse its possible relation to adolescents' quality of life. Methods: This is a cross-sectional analytical study with 363 adolescents from the Brazilian NGO. The instruments used included a short Portuguese version of the Integrated Questionnaire to Measure Social Capital (SC-QI) from the World Bank and its abbreviated Portuguese version from the World Health Organization Quality of Life Bref (WHOQoL-Bref) used to measure the quality of life. To measure social capital, the present study chose to use a segmentation analysis, along with the Two-Step Cluster method, applying Euclidian distance and the criteria of centroid aggregation. The MannWhitney test was used to compare the scores of WHOQOL-Bref domains among the clusters, at a significance level of $5 \%$. Results: The segmentation analysis resulted in two clusters, with 160 (44.1\%) adolescents classified as Low Social Capital (LSC) and 178 (49\%) classified as High Social Capital (HSC). Participation in activities for the good of the community $(p<0.001)$, opinion regarding the differences between people in the community $(p=0.002)$, and number of community meetings $(p<0.001)$ constituted the decisive variables for determining the separation of the clusters. When quality of life among the newly formed clusters was compared, the highest average score in the HSC cluster was found in the Psychological Domain (75.4 \pm 11.9 ), whereas in the LSC cluster, the highest average score was found in the Physical Domain (74.6 \pm 12.6). Lower quality of life scores was found in the environmental domain for both the LSC clusters $(51.3 \pm 14.0)$ and the HSC clusters $(54.7 \pm$ 15.5). This difference proved to be statistically significant $(p=0.009)$. Conclusions: The results showed that adolescents with higher social capital also presented higher scores concerning quality of life. For the studied population, a positive relation between the two concepts was verified.

Keywords: Social Capital; Quality of Life; Adolescent

\section{INTRODUCTION}

Putnam defines social capital as the characteristics of social structure that act as resources for people and facilitate collective action. This is a concept comprised of characteristics such as trust, reciprocal support, civic engagement, and identity within the community and social networks. The premise is that the levels of social class in a community have an important impact on one's well-being [1].

The participation of individuals in social and community networks is an integral part of social capital which grants the participants the capacity to persevere in search of common goals rather than their own personal interests [2]. Levels of social participation are significantly influenced by socio-economic level and health, 
among other demographic characteristics [3].

The aggregation of this type of resource can generate both individual and collective benefits, albeit over the long term. By contrast, social capital should not be considered a natural product, but rather something that must undergo constant development through individual and/or collective investment strategies [4]. Access to information or other goods and services, a sense of belonging, and social support can be considered as the individual effects of social capital; however, the construction process itself is a collective phenomenon.

Social capital can be constructed within the family, in relationships with neighbours, in the workplace, and in the community. In these environments, people establish primary relationships to confront day-by-day difficulties, in turn allowing for an improvement in their quality of life at micro levels, as in healthy behaviors, and at macro levels, as in more equal political processes [5].

Quality of life is understood by the World Health Organization (WHO) as an individual's perception of their position in life in the context of the culture and value systems in which they live, as well as in relation to their objectives, expectations, standards, and concerns [6].

Quality of life has become an ever-increasing focus of paediatrics and adolescent medicine in recent years, especially as regards stage of life of extreme importance in the construction of values that will guide an individual's adult life [7].

In terms of adolescence, prior research has commonly focused on the quality of life's impact on health [8-10]. Other studies have dealt with the association between social capital and health within the Brazilian population [11-13]. Research that investigates the association between quality of life and social capital in this age range is scarce, however, in this light, the present study aimed to measure social capital and analyse its possible relation to quality of life among adolescents.

\section{METHODS}

\subsection{Sample and Data Collection}

The present study is an analytical cross-sectional study whose reference population consists of all the adolescents from the philanthropic non-governmental organization (NGO), whose main offices are located in a midsized city in Brazil.

The adolescents are public school students aged from 16 to 18 years of age who come from economically vulnerable family environments $(\mathrm{N}=363)$. For this study, female adolescents were excluded (4.1\%).

The NGO carries out follow-up work with adolescent students through the promotion of educational and cultural activities of sports and leisure. These actions, developed in partnership with local authorities, are in- tended to contribute to the construction of social values and a sense of citizenship.

Data collection was carried out by means of questionnaires applied during one meeting held at the NGO's office, at which time all the adolescents were in attendance. This research was approved by the Research Ethics Committee from Universidade Federal de Minas Gerais (UFMG).

\subsection{Measures}

Socio-demographic information (age, sex, self-reported skin colour, and education level) was gathered from the adolescents. The instrument used to measure the quality of life was the validated and translated, abbreviated Portuguese version of the World Health Organization Quality of Life Bref (WHOQoL-Bref), designed for epidemiological studies, as developed by the Quality of Life Group from the WHO, known as the WHOQoL Group [14]. This questionnaire contains 26 questions and is divided into four domains: Physical (perception of the individual regarding their physical condition); Psychological (perception of the individual regarding their affective and cognitive condition); Social relations (perception of the individual regarding social relations and social roles adopted in life); Environmental (perception of the individual regarding diverse aspects related to the environment in which they live). This questionnaire does not conceptually defend the notion that one should use a total score of the quality of life, as it is possible to analyse each domain separately. The scale of values for each domain can vary from zero to 100 points, indicating that the higher the score, the better the quality of life in that domain.

The other questionnaire used in this study was the short version of the Integrated Questionnaire to Measure Social Capital (SC-QI) from the World Bank, divided into 27 questions and six dimensions [15]. The groups and networks dimension is more commonly associated with social capital and describes the nature, extension, and diversity of the participation of a member of a household in various types of social organizations and informal networks. The trust and solidarity dimension attempts to find data on trust of one's neighbours, essential service providers, and strangers, and how these perceptions change over time. The collective action dimension investigates how the individual has been working in collective community projects. The information sources dimension is related to the means through which households receive information regarding market conditions and public services and have access to communication infrastructures. Bearing in mind that the people of any one community can be quite different, the cohesion and social inclusion dimension attempts to identify the nature 
and size of these differences. The final dimension, empowerment and political action, verifies feelings of happiness, personal efficacy, and the ability of household members to influence both local events and broader political actions. The construction of a databank was performed with the Statistical Package for Social Sciences for Windows, version 17, for data analysis. First, the scores from each WHOQoL-Bref domain were calculated. Spearman's correlation coefficient was used to measure the degree of association among the WHOQoL domains.

\subsection{Statistical Analysis}

The SC-QI offers no specific type of scoring, which makes the standardization of the analysis difficult [15]. The literature shows that the questions are commonly analyzed individually [12]. The present study opted for the segmentation analysis in an attempt to compute the instrument variables collectively.

The segmentation analysis is a statistical tool which groups data together, placing similar cases within the same group according to the characteristics by which the data were measured [16].

This study applied the Two-Step Cluster method to group the sample as regards similarities in questionnaire answers, using the centroid (continuous variable) as a criterion to aggregate answers. The statistics program used the chi-squared test for categorical variables and the Student $t$ test for the continuous variable in an attempt to differentiate and determine the importance of each variable in the division of the clusters.

The segmentation also allows the researcher to choose which and how many variables will be inserted into the program, which is quite sensitive to the quantity of missing data. Initially we excluded the variable that pre- sented $10 \%$ or more of missing cases, which included nine questions. The SC-QI concentrates on the average micro level (household and individuals) and all dimensions that are important in formulating the concept of social capital [8]. This study chose to measure the social capital of this sample by selecting one single question from each dimension of the instrument in such a way as to contemplate all the dimensions of the SC-QI. Of the 18 remaining questions (three questions from the first dimension, six from the second, two from the third, two from the fourth, three from the fifth, and four from the final dimension), 864 possible combinations among the variables could be identified. All of these combinations were tested following the requirements set forth in previous literature $[17,18]$.

The first step to reduce the excess of differentiation is to gather clusters whose centroids are near each other; the second step is to discard any clusters made up by only a few elements, reassigning the elements to the surviving clusters. The final clustering solution is produced by aggregating the multiple clustering results through weighted voting.

At the end of the process, two clusters, with six variables each, were formed. The participation in groups measured by the number of social groups that adolescents regularly participate. This variable was selected by the program as the centroid of the clusters. Beginning with the centroid, the clusters were then separated by the other selected variables: willingness (time) to help in the community, participation in community activities for the good of the neighborhood, main information source, presence of differences within the neighborhood, and participation in community meetings (Figure 1).

The Mann-Whitney test was used to compare the scores of the WHOQoL-Bref domains within the clusters, at a significance level of $5 \%$.

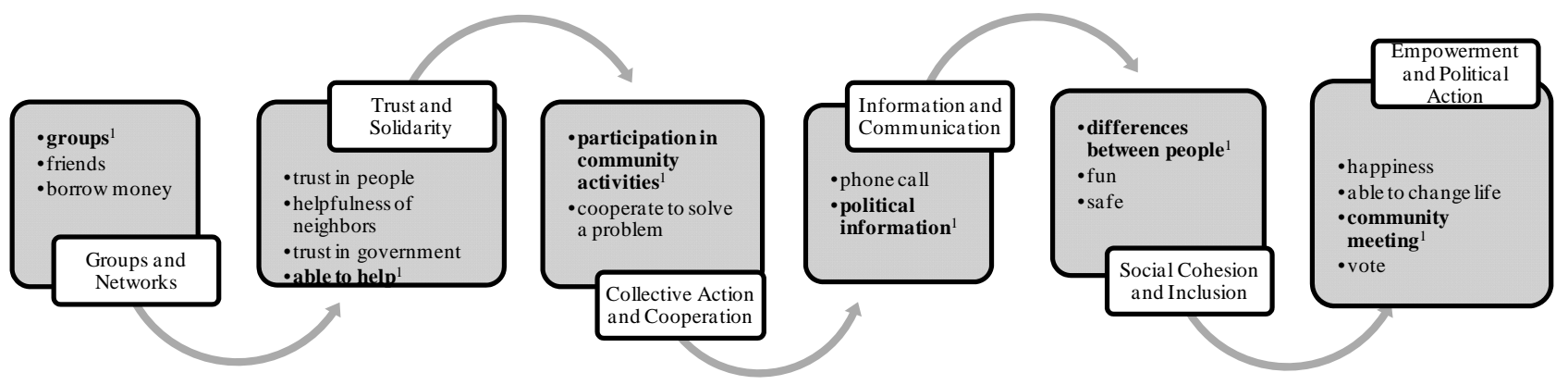

Figure 1. Questions of SC-QI selected through a simple arrangement for segmentation analysis. SC-QI Dimensions’: 1) Groups and Networks with 3 questions: groups; friends and borrow money; 2) Trust and Solidarity with 4 questions: trust in people; helpfulness of neighbors; trust in government and able to help; 3) Collective Action and Cooperation with 2 questions: participation in community activities and cooperate to solve a problem; 4) Information and Communication with 2 questions: phone call and political information; 5) Social Cohesion and Inclusion with 3 questions: differences between people; fun; safe; 6) Empowerment and Political Action with 4 questions: happiness; able to change life; community meeting and vote. ${ }^{1}$ Variables selected for segmentation analysis are marked in bold. 


\section{RESULTS}

Of the total number of adolescents in the study $(\mathrm{N}=$ 348), $50.6 \%$ were 16 years of age, $88.8 \%$ were in high school, and $13.8 \%$ reported being white (Table $\mathbf{1}$ ).

Figure 2 shows Spearman's correlation coefficient among the WHOQoL domains ( $\mathrm{p}<0.001)$, with the largest coefficients of correlation identified in the Psychological and Physical $\left(r^{2}=0.49\right)$ domains as well as in the Psychological and Environmental $\left(r^{2}=0.47\right)$ domains.

The segmentation analysis formed two clusters, with 208 (57.3\%) adolescents classified as Low Social Capital (LSC) and 116 (32.0\%) classified as High Social Capital (HSC); 39 adolescents were excluded from the study as they did not fit within either cluster. The adolescents' participation in groups was the centroid chosen by the segmentation analysis, given that the average participa-

Table 1. Demographic characteristics of 348 male adolescent workers.

\begin{tabular}{ccc}
\hline Variables categories & $\mathrm{n}$ & $\%$ \\
\hline Age & 09 & 2,6 \\
15 years old & 176 & 50,6 \\
16 years old & 163 & 46,8 \\
17 years old & & \\
Skin Color & 48 & 13,8 \\
White & 298 & 85,6 \\
No white & 02 & 0,6 \\
Not answered & & \\
Education & 39 & 11,2 \\
First degree & 309 & 88,8 \\
High school & & \\
\hline
\end{tabular}

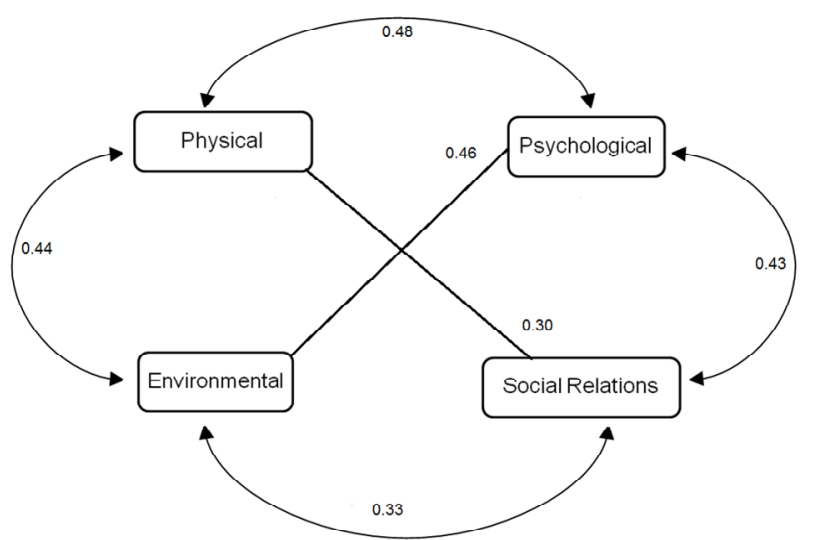

Figure 2. Correlation coefficient among adolescents' WHOQoL-Bref domains ${ }^{1}{ }^{1}$ Correlation is significant at the 0.01 level. The numbers represent the Spearman's correlation coefficient. tion by the groups of the HSC cluster was $3.0( \pm 2.9)$ and that of the LSC cluster was $2.8( \pm 2.9)$ but with no statistical significance $(p=0.610)$.

Table 2 presents the characteristics that define each cluster. Participation in activities for the good of the community ( $p<0.001$ ), main source of political information ( $p<0.001$ ), opinion regarding the differences between the people of the community $(p=0.006)$, and number of community meetings ( $p<0.001$ ) were the decisive variables in the separation of the clusters.

In the HSC cluster, the majority of adolescents could be willing to help in community projects (67.3\%), participate in activities for the good of the community

Table 2. Distribution of the variables selected from the SC-QI which defined the formation of the clusters.

\begin{tabular}{|c|c|c|c|c|c|}
\hline \multirow[t]{2}{*}{ Variables and categories } & \multicolumn{4}{|c|}{ Clusters } & \multirow[t]{2}{*}{ p-value ${ }^{1}$} \\
\hline & \multicolumn{2}{|c|}{$\begin{array}{l}\text { Low SC } \\
(\mathrm{N}=116)\end{array}$} & \multicolumn{2}{|c|}{$\begin{array}{l}\text { High SC } \\
(\mathrm{N}=208)\end{array}$} & \\
\hline \multirow{2}{*}{$\begin{array}{l}\text { Participation in groups (averages } \\
\text { and standard deviation) }\end{array}$} & \multicolumn{2}{|c|}{$3.0( \pm 2.9)$} & \multicolumn{2}{|c|}{$2.8( \pm 2.9)$} & 0.610 \\
\hline & $\mathrm{N}$ & $\%$ & $\mathrm{~N}$ & $\%$ & \\
\hline \multicolumn{6}{|l|}{$\begin{array}{l}\text { Willingness to help in } \\
\text { community projects }\end{array}$} \\
\hline Yes & 24 & 20.7 & 40 & 19.2 & \\
\hline Maybe & 62 & 53.4 & 100 & 48.1 & 0.436 \\
\hline No & 30 & 25.9 & 68 & 32.7 & \\
\hline \multicolumn{6}{|l|}{$\begin{array}{l}\text { Participation in activities for the } \\
\text { good of the community }\end{array}$} \\
\hline Yes & 00 & 0.0 & 105 & 50.5 & \\
\hline No & 116 & 100.0 & 103 & 49.5 & \\
\hline \multicolumn{6}{|l|}{ Main source of political information } \\
\hline Parents, friends, neighbours & 01 & 0.9 & 56 & 26.9 & \\
\hline Groups, associations, colleagues & 115 & 99.1 & 29 & 13.9 & $<0.001$ \\
\hline Television, radio, internet, others & 00 & 0.0 & 123 & 59.1 & \\
\hline \multicolumn{6}{|l|}{$\begin{array}{l}\text { Difference between people in the } \\
\text { community }\end{array}$} \\
\hline Quite different & 43 & 37.1 & 106 & 51,0 & \\
\hline Relatively different & 32 & 27.6 & 61 & 29.3 & 0.006 \\
\hline Little difference & 41 & 35.3 & 41 & 19.7 & \\
\hline \multicolumn{6}{|l|}{ Number of community meetings } \\
\hline Never & 106 & 91.4 & 69 & 33.2 & \\
\hline Once & 10 & 8.6 & 49 & 23.6 & $<0.001$ \\
\hline Sometimes & 00 & 0.0 & 90 & 43.3 & \\
\hline
\end{tabular}

${ }^{1}$ Chi-squared test for categorical variables and the student $t$ test for the continuous variable in an attempt to differentiate and determine the importance of each variable in the division of the clusters. 
(50.5\%), use television, radio, and internet as information sources (59.1\%), consider the people of the neighbourhood to be quite different $(51.0 \%)$, and they met once or more to request for something benefiting the community (66.9\%) (Table 2).

When the quality of life among the clusters was compared, the lower average scores for quality of life were found in the Environmental Domain for both LSC clusters $51.2( \pm 14.5)$ and HSC clusters $54.1( \pm 15.0)$. This difference proved to be statistically significant $(\mathrm{p}=0.016)$ (Table 3).

\section{DISCUSSION}

Although the adolescents in this study tended to be from less favorable socio-economic backgrounds, they did report a good quality of life in all WHOQoL domains. When the domains themselves were commented upon, a moderate correlation could be observed, with the most notable correlation occurring between the psychological and physical domains $\left(r^{2}=0.49\right)$.

These results may well explain the larger averages in the physical and psychological domains of the quality of life of the participants, regardless of the cluster to which they pertain. These results indicate how important physical self-evaluation and personal satisfaction are in adolescence [19].

The adolescents from the present study regularly have the opportunity to practice sports and do physical and recreational activities that are regularly promoted by the NGO, promoting health as well as the construction of solid companionship bonds among these adolescents. In general, regular physical exercise can aid in improving adolescents' quality of life, mainly as regards the physical domain [20]. The sport has great potential to build relationships and promote social cohesion [21].

The psychological domain considers safety and concentration in one's personal life and sense of being. The determining factors of the adolescents' quality of life appear to be mostly related to mental, emotional, and physical health [22,23].

By contrast, the adolescents in this study are constantly motivated to improve their capacity to think and

Table 3. WHOQoL-Bref domains according to the classification of the cluster regarding social capital.

\begin{tabular}{cccc}
\hline $\begin{array}{c}\text { WHOQoL-bref } \\
\text { Domains }\end{array}$ & $\begin{array}{c}\text { Low SC } \\
(\mathrm{N}=160)\end{array}$ & $\begin{array}{c}\text { High SC } \\
(\mathrm{N}=178)\end{array}$ & p-value $^{1}$ \\
\hline Physical $^{2}$ & $73.9( \pm 12.4)$ & $74.5( \pm 11.7)$ & 0.625 \\
Psychological $^{2}$ & $73.3( \pm 14.2)$ & $75.6( \pm 11.1)$ & 0.211 \\
Social Relations $^{2}$ & $69.3( \pm 15.8)$ & $75.4( \pm 14.8)$ & 0.062 \\
Environmental $^{2}$ & $51.2( \pm 14.5)$ & $54.1( \pm 15.0)$ & 0.016 \\
\hline
\end{tabular}

Abbreviations: SC: Social Capital; ${ }^{1}$ Mann-Whitney test; ${ }^{2}$ Scores presented in averages (standard deviation). learn, as well as that of memory and concentration, aspects which are also important when assessed by the psychological domain. Although it is not the focus of the present work, it is possible to infer that the cultural and leisure activities, as well as the NGO's follow-up on schoolwork, may well have a favorable impact on this issue.

Only in the environmental domain were the average scores below 70.0. One possible way to explore this finding is to raise hypotheses regarding the general conditions of life and housing for these adolescents. Care should be exercised, however, as it was not possible to verify other information about the life of the participants.

As regards social capital, the majority of adolescents (57.3\%) presented high social capital. Bearing in mind that this sample of adolescents pertains to economically vulnerable families, this finding can be considered positive.

On the basis of the concepts treated by the World Bank [15], it can be said that the two clusters are different as regards the stock of social capital. On the one hand is the cluster with low social capital, comprised of adolescents who seem to be more distant from community life and who are, to an extent, more individualistic. On the other hand, there is the cluster of adolescents with high social capital who proved to be the most participative within groups from both the neighborhood and the community.

Participation in activities for the good of the community ( $p<0.001)$ and in community meetings ( $p<0.001)$ presented the greatest difference identified by the analysis when comparing the two clusters. The participation of the adolescents in groups is not customary, since, at this age, interest in friendship tends to be more common. Nevertheless, the HSC cluster tends to participate more in groups than does the LSC cluster. The results also highlight other important differences between the two clusters, such as activities for the good of the community, which is a relevant aspect for a larger stock of social capital, as it allows for greater community action and empowerment [24].

The present study sought to analyze the presence of social capital among adolescents and establish associations with their quality of life. It could be observed that the HSC cluster, as compared with the LSC cluster, presented a higher average in all WHOQoL-Bref domains, and these differences proved to be statistically significant in the Environmental Domain ( $p=0.016$ ).

Communities with a high stock of social capital tend to present better results in physical health, even when their environments are poor [25]. In Brazil, studies have reported an association between interpersonal relations, social capital, and health [11-13].

Research similar to the present study that seeks to 
analyze social capital and its implication on the quality of life $[5,25]$ is still rare, however, especially concerning adolescents [26,27]. The results from the present study indicate that social capital and quality of life are related. Nonetheless, it was impossible to measure the intensity of this relationship or the contextual effects and social changes that can occur over time.

When adolescents are capable of interacting positively with the world around them, be that in school, at home, or in the neighborhood, in a productive and creative manner, and even when placed in a challenging situation, a greater autonomy and competence within the sociocultural context to which they belong can be observed.

Adolescents who rely on social support networks tend to be more socially competent and enjoy higher levels of quality of life than those who interact only with their family or friends $[28,29]$. By contrast, this lack of support can bring about negative consequences for the adolescents [30,31].

These factors appear to represent important steps to combat poverty, promote educational reforms, and foster the development of competencies and social integration of the youth, given that participation in the community and the comprehension of the mechanisms needed to function properly are the pillars of effective social policies $[32,33]$. There is a growing desire to construct a new perspective on health which seeks access to the population's knowledge as well as to greater participation and social cohesion. This need seems feasible within the perspectives of quality of life and social capital.

A better comprehension of the mechanisms tied to these two concepts may well bring about more effective interventions and policies aimed at promoting the general health of the population [4,34].

\section{Limitations}

The present study's sample was limited in its socioeconomic aspects, which reduce the over-generalization of the results, given that the requirements used to admit adolescents within the NGO (age, income, and education level) explain the homogeneity of the sample.

The segmentation analysis is a statistical tool that depends heavily on the researchers' knowledge of the theme when interpreting data. By contrast, it is also ideal for homogeneous samples, since the grouping occurs by means of the approximation of these similarities and differences among the individuals, thus allowing for a reliable separation of the groups [13].

Although there are important studies concerning social capital and health of adolescents in Brazil [12,23,25], the reliability of the SC-QI as a whole has yet to be tested in this Brazilian population. This study represents one of the few to use all of the questionnaire's questions in a sample of Brazilian adolescents. The design of the cross- sectional study, however, does not allow one to evaluate the causal relationship between social capital and adolescents' quality of life.

Therefore, the use of social capital should not be applied in an acritical manner as the sole solution to all health problems. In fact, the effect of social capital on health must be considered within the context of social and political environments [35]. As regards the quality of life, we need more population studies and comparable measures for different contexts [36].

In conclusion, the present study showed that adolescents with a higher social capital also presented higher scores regarding their quality of life. This means that, for the studied population, it was possible to verify a positive relationship between the two concepts.

Follow-up with the adolescents carried out by the NGO may well play a key role in the findings of this study, but this relationship was impossible to measure. Nevertheless, the daily routine within this NGO appears to contribute to the creation of stronger ties and friendships among the adolescents through the sharing of experiences and growing together. These stable and longlasting social relations represent an excellent indicator of the stock of social capital and a good quality of life.

\section{ACKNOWLEDGEMENTS}

We are grateful to all the staff and participants in the NGO, especially Oldac Campos. We would also like to thank CNPq and FAPEMIG for their financial support; and Thiago Henrique Pereira Nunes for participating in the data collection.

\section{REFERENCES}

[1] Putnam, R.D. (1993) Making democracy work, civic traditions in modern Italy. Princeton University Press, Princeton.

[2] Putnam, R.D. and Goss, K.A. (2002) Introduction. In: Putnam, R.D., Ed., Democracies in Flux, Oxford University Press, New York, 3-19. doi:10.1093/0195150899.003.0001

[3] Baum, F.E., Bush, R.A., Modra, C.C., Murray, C.J., Cox, E.M., Alexander, K.M. and Potter, R.C. (2000) Epidemiology of participation: An Australian community study. Journal of Epidemiology \& Community Health, 54, 414423. doi:10.1136/jech.54.6.414

[4] Kawachi, I. and Berkman, L.F. (2000) Social cohesion, social capital and health. In: Berkman, L.F. and Kawachi, I., Eds., Social Epidemiology, Oxford University Press, New York, 147-190.

[5] Nilsson, J., Rana, A.K.M.M. and Kabir, Z.N. (2006) Social capital and quality of life in old age: Results from a cross-sectional study in rural Bangladesh. Journal of Aging and Health, 3, 419-434. doi:10.1177/0898264306286198

[6] The WHOQoL Group (1995) The World Health Organi- 
zation Quality of Life assessment (WHOQoL): Position paper from the World Health Organization. Social Science \& Medicine, 10, 1403-1409.

[7] Barker, G. (2007) Adolescents, social support and helpseeking behavior: An international literature review and program consultation with recommendations for action. Department of Child and Adolescent Health and Development, World Health Organization: WHO discussion papers on adolescence.

http://www.who.int/child adolescent health/documents/9 789241595711/en/index.html

[8] Edwards, T.C., Huebner, C.E., Connell, F.A. and Patrick, D.L. (2002) Adolescent quality of life, part I: Conceptual and measurement model. Journal of Adolescence, 25, 275-286. doi:10.1006/jado.2002.0470

[9] Drukker, M., Kaplan, C., Schneiders, J., Feron, F.J.M. and van Os, J. (2006) The wider social environment and changes in self-reported quality of life in the transition from late childhood to early adolescence: A cohort study. BMC Public Health, 6, 133. doi:10.1186/1471-2458-6-133

[10] Polinder, S., Haagsma, J.A., Belt, E., Lyons, R.A., Erasmus, V., Lund, J., et al. (2010) A systematic review of studies measuring health-related quality of life of general injury populations. BMC Public Health, 10, 783. doi:10.1186/1471-2458-10-783

[11] Borges, C.M., Campos, A.C.V., Vargas, A.M.D., Ferreira, E.F. and Kawachi, I. (2010) Social capital and self-rated health among adolescents in Brazil: An exploratory study. BMC Research Notes, 3, 338.

http://www.biomedcentral.com/1756-0500/3/338

[12] Patussi, M.P., Hardy, R. and Sheiham, A. (2006) Neighborhood social capital and dental injuries in Brazilian adolescents. American Journal of Public Health, 96, 14621468. doi:10.2105/AJPH.2005.066159

[13] Patussi, M.P., Hardy. R. and Sheiham, A. (2006) The potential impact of neighborhood empowerment on dental caries among adolescents. Community Dentistry and Oral Epidemiology, 34, 344-350. doi:10.1111/j.1600-0528.2006.00283.x

[14] Fleck, M.P.A., Louzada, S., Xavier, M., Chachamovich, E., Vieira, G., Santos, L., et al. (2000) Application of the Portuguese version of the abbreviated instrument of quality life WHOQoL-bref. Revista de Saúde Pública, 2, 178183. doi:10.1590/S0034-89102000000200012

[15] Grootaert, C., Narayan, D., Jones, V.N. and Woolcock, M. (2003) Integrated questionnaire for the measurement of social capital (SC-IQ). World Bank, Washington DC. http://www.contentdigital.com.br/textos/comunidades/Qu estionario\%20Integrado\%20para\%20medir\%20Capital\% 20Social\% 20Banco\%20Mundial.pdf

[16] Hair, J.F., Black, W.C., Babin, J.B. and Anderson, R.E., Tatham, R.L. (2009) Segmentation analysis. In: Hair, J.F., Black, W.C., Babin, J.B., Anderson, R.E. and Tatham, R.L., Eds., Multivariate Data Analysis, 6th Edition, Prentice-Hall, Upper Saddle River, 427-481.

[17] Woolcock, M. (1998) Social capital and economic development: Toward a theoretical synthesis and policy framework. Theory and Society, 27, 151-208.
doi:10.1023/A:1006884930135

[18] Woolcock. M. and Narayan, D. (2000) Social capital: Implications for development theory, research, and policy. World Bank Research Observer, 15, 225-250. doi:10.1093/wbro/15.2.225

[19] Jozefiak, T., Larsson, B. and Wichstrøm, L. (2009) Changes in quality of life among Norwegian school children: A six-month follow-up study. Health and Quality of Life Outcomes, 7, 7. doi:10.1186/1477-7525-7-7

[20] Brown, D.W., Balluz, L.S., Heath, G.W., Moriarty, D.G., Ford, E.S., Giles, W.H., et al. (2003) Associations between recommended levels of physical activity and healthrelated quality of life findings from the 2001 Behavioral Risk Factor Surveillance System (BRFSS) survey. Preventive Medicine, 5, 520-528. doi:10.1016/S0091-7435(03)00179-8

[21] Delaney, L. and Keaney, E. (2005) Sport and social capital in the United Kingdom: Statistical evidence from national and international survey data. Economic and Social Research Institute, Institute for Public Policy Research, Dublin.

[22] Zullig, K.J., Valois, R.F. and Drane, J.W. (2005) Adolescent distinctions between quality of life and self-rated health in quality of life research. Health Qual Life Outcomes, 3, 64. doi:10.1186/1477-7525-3-64

[23] Rajmil, L., Palacio-Vieira, J.A., Herdman, M., LópezAguilà, S., Villalonga-Olives, E., Valderas, J.M., et al. (2009) Effect on health-related quality of life of changes in mental health in children and adolescents. Health and Quality of Life Outcomes, 7, 103. doi:10.1186/1477-7525-7-103

[24] Duke, N.N., Skay, C.L., Pettingell, S.L. and Borowsky, I.W. (2009) From adolescent connections to social capital: Predictors of civic engagement in young adulthood. Journal of Adolescent Health, 44, 161-168. doi:10.1016/j.jadohealth.2008.07.007

[25] Modie-Moroka, T. (2009) Does level of social capital predict perceived health in a community? A study of adult residents of low-income areas of Francistown, Botswana. Journal of Health, Population and Nutrition, 27, 462-476. doi:10.3329/jhpn.v27i4.3390

[26] Drukker, M., Kaplan, C.D., Feron, F.J.M. and Van Os, J. (2003) Children's health-related quality of life, neighbourhood socio-economic deprivation and social capital. A contextual analysis. Social Science \& Medicine, 57, 825-841. doi:10.1016/S0277-9536(02)00453-7

[27] Morrow, V. (2001) Using qualitative methods to elicit young people's perspectives on their environments: Some ideas for community health initiatives. Health Education Research, 16, 255-268. doi:10.1093/her/16.3.255

[28] Sherbourne, C.D., Meredith, L.S., Rogers, W. and Ware Jr., J.E. (1992) Social support and stressful life events: Age differences in their effects on health-related quality of life among the chronically ill. Quality of Life Research, 1, 235-246. doi:10.1007/BF00435632

[29] Villalonga-Olives, E., Rojas-Farreras, S., Vilagut, G., Palacio-Vieira, J.A., Valderas, J.M., Herdman, M., et al. (2010) Impact of recent life events on the health related quality of life of adolescents and youths: The role of gender and 
life events typologies in a follow-up study. Health and Quality of Life Outcomes, 8, 71. doi:10.1186/1477-7525-8-71

[30] Aro, H., Hänninen, V. and Paronen, O. (1989) Social support, life events and psychosomatic symptoms among 14 16-year-old adolescents. Social Science \& Medicine, 29, 1051-1056. doi:10.1016/0277-9536(89)90015-4

[31] Caughy, M.O.B., O’Campo, P.J. and Muntaner, C. (2003) When being alone might be better: neighborhood poverty, social capital, and child mental health. Social Science \& Medicine, 57, 227-237. doi:10.1016/S0277-9536(02)00342-8

[32] Giordano, G.N. and Lindstrom, M. (2010) The impact of changes in different aspects of social capital and material conditions on self-rated health over time: A longitudinal cohort study. Social Science \& Medicine, 70, 700-710. doi:10.1016/j.socscimed.2009.10.044

[33] Berg-Kelly, K. (2003) Adolescent health, school health activities, community contexts, and health surveys in Sweden. Journal of Adolescent Health, 4, 226-230. doi:10.1016/S1054-139X(03)00098-3

[34] Kim, D. and Kawachi, I. (2006) A multilevel analysis of key forms of community-and individual-level social capital as predictors of self-rated health in the United States. Journal of Urban Health: Bulletin of the New York Academy of Medicine, 5, 813-826.

[35] Boyce, W.F., Davies, D., Gallupe, O. and Shelley, D. (2008) Adolescent risk taking, neighborhood social capital, and health. Journal of Adolescent Health, 43, 246-252. doi:10.1016/j.jadohealth.2008.01.014

[36] Baumann, C., Erpelding, M.L., Perret-Guillaume, C., Gautier, A., Régat, S., Collin, J.F., et al. (2011) Healthrelated quality of life in French adolescents and adults: Norms for the DUKE health profile. BMC Public Health, 11, 401. doi:10.1186/1471-2458-11-401 